\title{
Estabilidade temporal da potenciometria e da salinidade em vale aluvial no semiárido de Pernambuco
}

\author{
Robertson V. de P. Fontes Júnior ${ }^{1}$, Abelardo A. A. Montenegro ${ }^{1}$, \\ Suzana M. G. L. Montenegro ${ }^{2} \&$ Thais E. M. dos Santos ${ }^{3}$
}

\begin{abstract}
RESU M O
As restrições no uso e na disponibilidade das águas subterrâneas nos aluviões do semiárido nordestino estão diretamente ligadas à sazonalidade e à variabilidade espacial de seus níveis potenciométricos e salinidade. A estabilidade temporal é de grande interesse, por facilitar o monitoramento, possibilitando se obter locais representativos acerca da área em estudo, constituindo-se em uma importante ferramenta para a gestão dos recursos hídricos subterrâneos. Com isto, o objetivo deste trabalho foi identificar áreas com estabilidade temporal do nível potenciométrico e da salinidade, em aquífero aluvial do Agreste Pernambucano. Foram utilizados o método das diferenças relativas e a validação por correlação entre a média no tempo do piezômetro estável e a média dos demais piezômetros. Quanto ao nível potenciométrico identificaram-se áreas estáveis que representam o comportamento médio enquanto para a salinidade as áreas estáveis não representam adequadamente a média do vale aluvial devido, possivelmente, às restrições de circulação hídrica e ao uso agrícola do solo.
\end{abstract}

Palavras-chave: diferença relativa da média, agricultura familiar, condutividade elétrica

\section{Temporal stability of piezometric levels and salinity in an alluvial valley in the semiarid Pernambuco - Brazil}

\begin{abstract}
A B ST RACT
The restrictions in the use and availability of groundwater in all uvial aquifers of the northeastern semiarid are directly related to seasonal and spatial variability of piezometric levels and salinity. Temporal stability is of high interest for monitoring, allowing representative locations about the studied area to be identified, being an important tool for groundwater resources management. Thus, the objective of this work was to identify areas with temporal stability for the water table level and salinity in an alluvial aquifer in the 'Agreste' region of Pernambuco State in Brazil. The relative difference method was used and also the validation by correlation between the mean response of one stable piezometer against the mean of all other piezometers, performed in time. For the water table level, stable areas representing the mean behavior were identified, while the stable areas for salinity did not represented well the mean behavior, perhaps due to flow restriction, and also due to agricultural soil use.
\end{abstract}

Key words: mean relative difference, communal farm, electrical conductivity

\footnotetext{
${ }^{1}$ DTR/U FRPE. R. Dom M anoel de Medeiros, s/n, Dois Irmãos, CEP 52.171-900, Recife, PE. Fone: (81) 3320-6264. E-mail: rr_fontes@hotmail.com; abelardo.montenegro@yahoo.com.br

${ }^{2}$ D ECIV/U FPE, Av. A cadêmico Hélio Ramos, s/n. Cidade U niversitária. CEP 50.740-530. Recife, PE. Fone: (81) 2126 7216. E-mail: suzanam@ufpe.br ${ }^{3}$ CCAAB/U FRB, Rua Rui Barbosa, 710, Centro, Cep: 44.380-000, Cruz das Almas, BA. E-mail: thaisemanuelle@ufrb.edu.br
} 


\section{INTRODUÇÃO}

Os recursos hídricos subterrâneos aluviais são estratégicos para as populações rurais no semiárido brasileiro. As restrições no uso e na disponibilidade das águas subterrâneas nos aluviões estão diretamente ligadas à sazonalidade e à variabilidade espacial de seus níveis e salinidade, requerendo monitoramento sistemático de sua quantidade e qualidade. O monitoramento e a interpretação da potenciometria e da salinidade da água nessas regiões, contribuem para o desenvolvimento da irrigação sendo relevantes para sustentabilidade local (Mackay et al., 2006).

As águas dos aquíferos aluviais do Nordeste brasileiro sofrem importantes diluições iônicas e recargas decorrentes das chuvas, que interferem na dinâmica temporal das concentrações de sais (Audry \& Suassuna, 1995). Adicionalmente, a circulação hídrica interfere na distribuição espacial da salinidade, a qual é influenciada pela condutividade hidráulica do meio poroso (Montenegro et al., 2003) pela distância transversal do ponto de interesse à calha do rio, pelos mecanismos de diluição (Burte et al., 2011) e pela distribuição espacial das zonas de recarga e descarga (Tweed et al., 2011).

A agricultura irrigada nas zonas semiáridas é praticada sobremaneira nos períodos secos, quando a demanda hídrica é mais elevada e as chuvas são insuficientes para o suprimento de água aos cultivos. Segundo Andrade (2009) a irrigação nessas regiões aumenta o risco de degradação ambiental promovendo mudanças no regime hidrológico, passível de gerar acúmulo de sais no solo, ascensão capilar, depleção dos aquíferos e transporte de solutos ao longo do perfil.

Vários estudos têm sido conduzidos no vale aluvial de Nossa Senhora do Rosário, PE, estudado nesta investigação com o intuito de caracterizar seu potencial para a agricultura irrigada e minimizar os riscos de salinização. O monitoramento da potenciometria e da condutividade elétrica da água foi iniciado em 1995 e reportado primeiro por Montenegro (1997) sendo realizado mensalmente até os dias atuais em um conjunto de transectos de 60 piezômetros. Montenegro et al. (2003) investigaram a dinâmica hidrossalina do aquífero aluvial, em resposta a eventos de chuva e ao uso agrícola; Montenegro \& Montenegro (2006) avaliaram a relação entre variabilidade espacial da salinidade, a textura e a condutividade hidráulica do solo, de modo a identificar áreas com maior aptidão para cultivos; Bastos et al. (2009) investigaram o desempenho do manejo da irrigação com água subterrânea salina e lixiviação reduzida, tendo observado a relevância das chuvas intensas na lavagem dos solutos na zona não saturada; Montenegro et al. (2010a) calibraram e validaram o modelo SALTMED utilizando medições de potencial matricial e de salinidade em lotes experimentais, para análise de alternativas do manejo da irrigação com águas subterrâneas, de forma a otimizar a produção agrícola em escala familiar; Montenegro et al. (2010b) avaliaram a salinidade aparente do solo e sua variabilidade utilizando dispositivo de indução eletromagnética, particularmente no eixo principal do vale e Andrade et al. (2012) estudaram a variabilidade espacial da condutividade elétrica das águas subterrâneas neste aluvião.
Entretanto, o monitoramento sistemático e distribuído é um procedimento oneroso justificando a investigação e a aplicação de técnicas que possibilitem a identificação de locais representativos da área de interesse. Para reduzir o número de amostras requeridas para um monitoramento adequado, Vachaud et al. (1985) propuseram uma metodologia que associa a estabilidade no tempo entre locações espaciais e valores estatísticos paramétricos clássicos. A teoria da estabilidade tem sido muito empregada em hidrologia; por exemplo, Sophocleous (1991) observou que a variabilidade temporal do armazenamento de água na zona não saturada de um aquífero freático era similar entre todas as locações monitoradas e, assim, verificou estacionaridade na flutuação dos níveis potenciométricos e no processo de recarga subterrânea; Brooca et al. (2009), Melo Filho \& Libardi (2005) e Martínez-Fernández \& Ceballos $(2003 ; 2005)$ verificaram a existência de locais representativos para a umidade média do solo reduzindo, então, os custos associados ao monitoramento; Moiwo et al. (2009), validaram, utilizando o mesmo método na análise da umidade do solo e nível potenciométrico de aquífero freático, informações estimadas a partir de imagens de satélite e de medições em locais representativos. Investigando a influência da cobertura morta na dinâmica temporal e espacial da umidade do solo, Santos et al. (2010) e Souza et al. (2011) utilizaram a metodologia de estabilidade temporal e identificaram áreas estáveis quanto à umidade média do solo, o primeiro nas encostas do vale aluvial e o segundo em um lote experimental piloto com cenoura irrigada, ambos na mesma bacia hidrográfica estudada nesta investigação.

O objetivo deste estudo foi avaliar a estabilidade temporal do nível potenciométrico e da salinidade da água subterrânea em aquífero aluvial no semiárido, em que se pratica agricultura irrigada de base familiar, avaliados sistematicamente em piezômetros, buscando-se identificar áreas representativas do comportamento médio do aquífero.

\section{Material e MÉTODOS}

O estudo foi realizado na Bacia do Riacho Mimoso, subbacia do Alto Ipanema (Figura 1) localizada no município de Pesqueira, Região do Agreste Pernambucano. O vale aluvial de Nossa Senhora do Rosário é circundado por encostas e possui embasamento cristalino relativamente raso. Segundo Montenegro (1997) o aquífero apresenta profundidade média de $10 \mathrm{~m}$, com cerca de $15 \mathrm{~km}$ de extensão e $0,3 \mathrm{~km}$ de largura. $\mathrm{O}$ clima é do tipo BSsh (extremamente quente, semiárido) de acordo com a classificação de Köppen, com pluviometria média anual de 607 mm (Santos et al., 2012). Aárea de estudo possui uma malha de poços de bombeamento e piezômetros georreferenciados; cada piezômetro possui cerca de $6 \mathrm{~m}$ de profundidade e diâmetro de $75 \mathrm{~mm}$. Existem na área, atualmente, 60 piezômetros em funcionamento e 28 poços de grande diâmetro utilizados para irrigação. Esses piezômetros foram instalados em julho de 1995, para estudo hidrológico por Montenegro (1997) que mediu a condutividade hidráulica da zona saturada, a qual apresenta distribuição log normal, com média geométrica de 5,80 $\mathrm{m} \mathrm{d}^{-1}$ e mediana de 5,90 $\mathrm{m} \mathrm{d}^{-1}$, com 


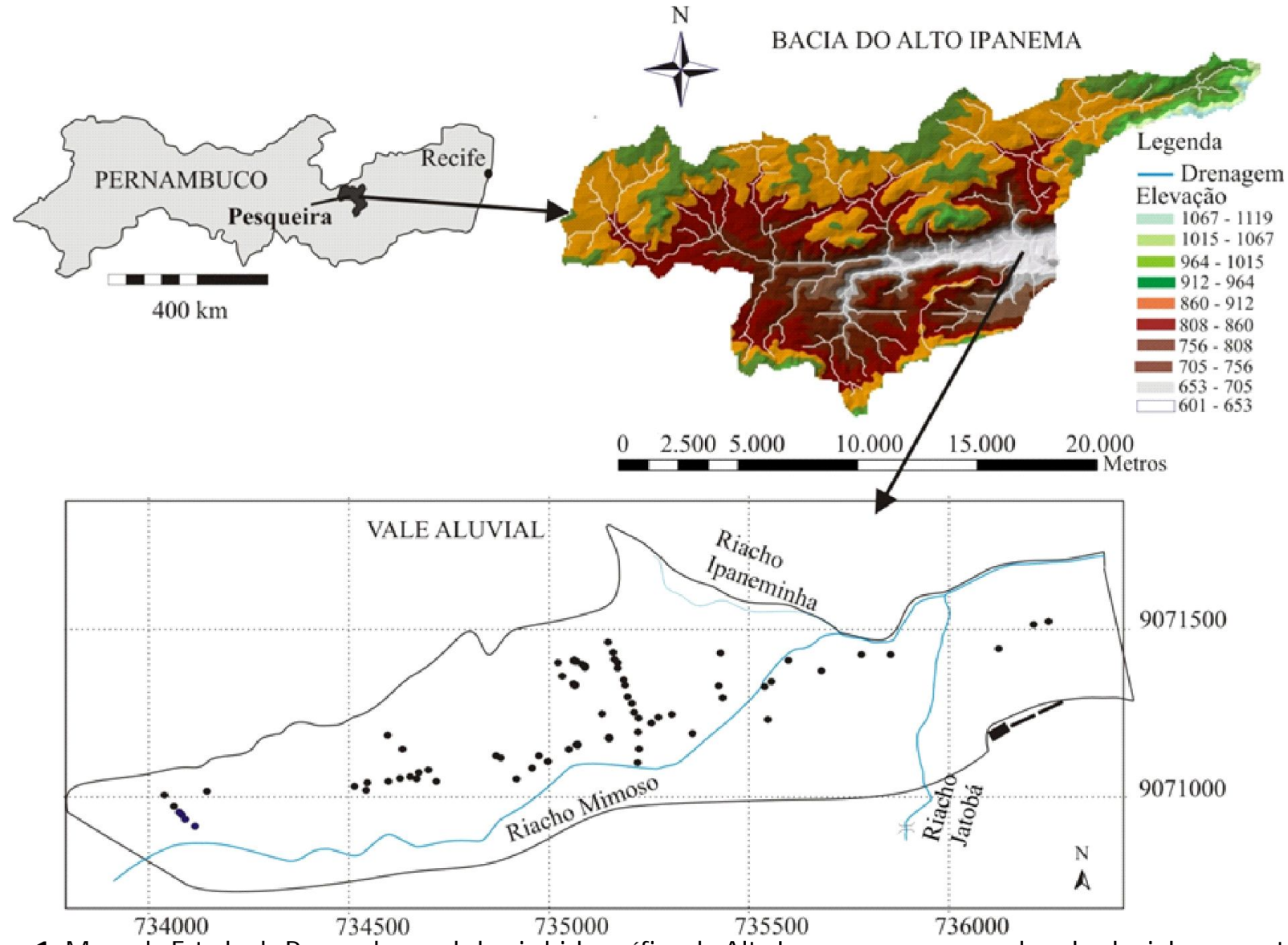

Figura 1. Mapa do Estado de Pernambuco, da bacia hidrográfica do Alto Ipanema e esquema do vale aluvial, apresentando a malha de piezômetros

base na distribuição de probabilidade dos logaritmos. O monitoramento é conduzido mensalmente através de leituras do nível da água nos piezômetros e coleta de amostra da água para medição da sua condutividade elétrica. Para este estudo foram utilizados 56 piezômetros no período de outubro de 2005 a junho de 2010, contabilizando-se 57 meses de monitoramento.

A Figura 1 apresenta a localização da área de estudo podendo-se visualizar, também, o modelo digital da bacia de contribuição e a região na qual o vale aluvial se desenvolve.

Segundo Corrêa \& Ribeiro (2001) os solos do vale aluvial são Neossolos Regolíticos e Neossolos Flúvicos, ocorrendo associações com Neossolos Litólicos em parte do contorno do vale.

As principais culturas exploradas no aluvião são pimenta, cenoura, beterraba, repolho, pimentão e tomate, todas com sistema radicular raso e com duas a três colheitas por ano. Em geral, os lotes irrigados são de pequenas dimensões, com cerca de 1 ha predominando a irrigação por aspersão observando-se crescente adoção da microaspersão e do gotejamento comumente, irriga-se uma vez por dia, a depender da ocorrência de chuvas.

Considerando-se que o estudo buscou identificação de piezômetros representativos do comportamento geral do vale, eliminaram-se os valores discrepantes seguindo-se o critério de Hoaglin et al. (1983) que considera discrepantes os valores abaixo do limite inferior ( $\mathrm{Li}$ ) ou acima do limite superior (Ls) respectivamente, estimados pelas (Eqs.1 e 2):

$$
\begin{aligned}
& \mathrm{Li}=\mathrm{Qi}-1,5 \mathrm{Ai} \\
& \mathrm{Ls}=\mathrm{Qs}+1,5 \mathrm{Ai}
\end{aligned}
$$

em que:

Qi e Qs são os quartis inferior e superior, respectivamente e Ai a amplitude interquartílica; a distribuição estatística das variáveis foi representada através de Box-plots.

Para a análise de estabilidade temporal no período de estudo quanto ao nível e à condutividade elétrica, foi utilizada a técnica proposta por Vachaud et al. (1985), baseada no cálculo da diferença relativa a qual permite a análise dos desvios entre os valores observados individualmente no espaço e a média entre eles. Com os valores de nível ( $\mathrm{m}$ ) e condutividade elétrica (dS $\mathrm{m}^{-1}$ ) avaliados mensalmente, foram calculadas as diferenças relativas para todos os piezômetros, de acordo com a Eq. 3:

$$
\delta_{i j}=\frac{X_{i j}-\bar{X}_{j}}{\bar{X}_{j}}
$$

em que $\mathrm{X}_{\mathrm{j}}$ é a média da variável no instante j, calculada como (Eq. 4):

$$
\bar{X}_{j}=\frac{1}{N} \sum_{i=1}^{N} X_{i j}
$$


donde $\mathrm{d}_{\mathrm{ij}}$ é a diferença relativa entre a determinação individual para um local i no tempo $\mathrm{j} ; \mathrm{X}_{\mathrm{ij}}$ o nível piezométrico ou a condutividade elétrica no local i e no tempo $\mathrm{j} ; \mathrm{X}_{\mathrm{j}}$ o valor médio do nível ou da condutividade elétrica para todas as $\mathrm{N}$ posições, no momento j. A média da diferença relativa para cada locação é definida pela Eq. 5:

$$
\overline{\delta_{i}}=\frac{1}{\mathrm{~m}} \sum_{\mathrm{j}=1}^{\mathrm{m}} \delta_{\mathrm{ij}}
$$

sendo m o número de meses estudados.

Para o desvio padrão temporal para cada locação pode-se empregar a Eq. 6:

$$
\sigma_{i}=\sqrt{\frac{1}{m-1} \sum_{j=1}^{m}\left(\delta_{i j}-\overline{\delta_{i}}\right)^{2}}
$$

A validação dos piezômetros estáveis foi realizada através da análise da correlação entre a média da resposta do piezômetro estável e a média de todos os demais piezômetros (MartínezFernández \& Ceballos, 2005).

Avaliou-se o grau de correlação tomando-se por base o erro aleatório, o qual indica o nível de dispersão dos dados obtidos em relação à média. A precisão da análise está relacionada à similaridade entre os valores no piezômetro estável e a média nos demais piezômetros. Matematicamente, esta similaridade pode ser avaliada através do índice de concordância (d) (Willmott et al., 1985) dado pelas expressões (Eqs. 7 e 8):

$$
\begin{gathered}
d=1-\frac{\sum_{j=1}^{m}\left(\hat{y}_{j}-y_{j}\right)^{2}}{\sum_{j=1}^{m}\left(\left|\hat{y}_{j}^{\prime}\right|+\left|y_{j}^{\prime}\right|\right)^{2}} \\
y_{j}^{\prime}=y_{j}-\bar{y} \\
\hat{y}_{j}^{\prime}=\hat{y}_{j}-\bar{y}
\end{gathered}
$$

sendo:

$\mathrm{d}$ - adimensional variando de 0 a 1

$\mathrm{y}_{\mathrm{j}}$ - valor no piezômetro estável no tempo $\mathrm{j}$

$\mathrm{y}_{\mathrm{j}}$ - valor médio nos demais piezômetros no tempo $\mathrm{j}$

y - média global dos valores nos demais piezômetros

Os valores de (d) variam de zero para nenhuma concordância, a 1, para concordância perfeita. Para indicar o desempenho da estabilidade nos piezômetros utilizou-se o índice (c) proposto por Camargo \& Sentelhas (1997) reunindo-se os coeficientes de correlação (r) e o de concordância (d), da seguinte forma (Eq. 9):

$$
\mathrm{c}=\mathrm{r} \times \mathrm{d}
$$

Os critérios para interpretar o desempenho da estabilidade dos piezômetros são apresentados na Tabela 1:

Tabela 1. Critério de interpretação do desempenho da estabilidade dos piezômetros, pelo índice "c"

\begin{tabular}{lc}
\hline Desempenho & Valor de "c" \\
Ótimo & $\geq 0,85$ \\
Muito bom & $0,76-0,85$ \\
Bom & $0,66-0,75$ \\
Mediano & $0,61-0,65$ \\
Sofrível & $0,51-0,60$ \\
Mal & $0,41-0,50$ \\
Péssimo & $\leq 0,40$ \\
\hline
\end{tabular}

Fonte: adaptado de Camargo \& Sentelhas (1997)

Além do uso do coeficiente de concordância foi avaliado o coeficiente de determinação entre os valores medidos nos piezômetros estáveis e os valores médios nos demais piezômetros, para o nível de água e salinidade, ao longo do tempo.

A Figura 2 apresenta os níveis potenciométricos e a salinidade das águas subterrâneas evidenciando-se a recuperação do lençol em resposta a eventos de chuva, assim como um comportamento sazonal dos níveis, de outubro de 2005 a julho de 2010. As estações chuvosas ocorreram nos meses de abril a julho e as secas de agosto a março, tendo pluviosidade média anual do acumulado mensal do período analisado de $1121 \mathrm{~mm}$.

\section{RESULTADOS E DISCUSSÃO}

Na Figura 3A tem-se a representação da distribuição espaçotemporal, em forma de Box-plot, das médias temporais do nível e da condutividade elétrica (CE) de todos os piezômetros, no período analisado. Observa-se a presença de valores discrepantes e extremos. Na Figura 3A também estão representados os box-plots dos valores de nível e CE, após filtragem das discrepâncias enquanto na Figura 3B estão representadas as médias temporais para os períodos secos e chuvosos, após a retirada de valores discrepantes.

Nos valores discrepantes foram observados piezômetros localizados em área de solos salinos sódicos (RU6, apresentada na Figura 4). Referidas discrepâncias interferem no comportamento da estabilidade aumentando os desvios em torno da média alterando, com isto, a representatividade de piezômetros estáveis. Nota-se, entretanto, que não houve alteração nos valores da mediana após a filtragem dos valores atípicos. $\mathrm{O}$ comportamento robusto da mediana da condutividade elétrica da água também foi verificado por Andrade et al. (2012) analisando a estrutura de dependência espacial desta variável em piezômetros do mesmo vale, nos meses de abril, julho e outubro dos anos de 2007, 2008 e 2009.

Por outro lado, verifica-se diferença entre as medianas dos níveis potenciométricos para as estações seca e chuvosa. Para a condutividade elétrica tal diferença entre as medianas nãoé observada. Burte et al. (2011) também constataram, investigando a dinâmica hidrossalina em aquífero aluvial no Ceará, que o comportamento dos níveis potenciométricos é claramente 


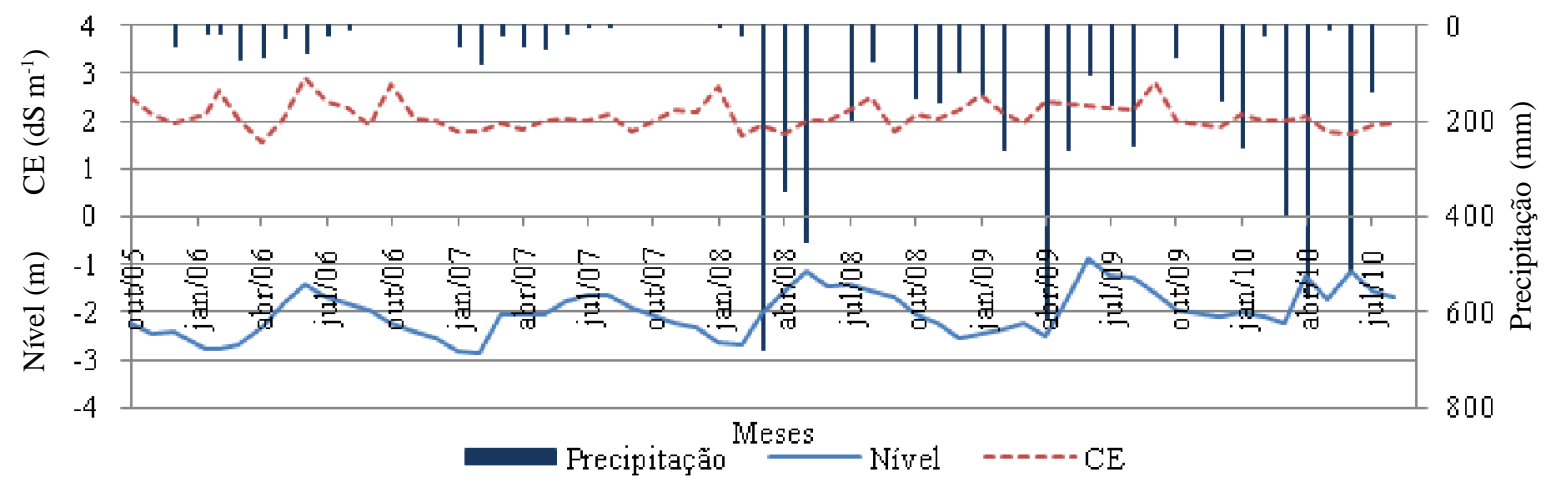

Figura 2. Série temporal de níveis potenciométricos médios, de salinidade média e precipitação no aluvião estudado

A.

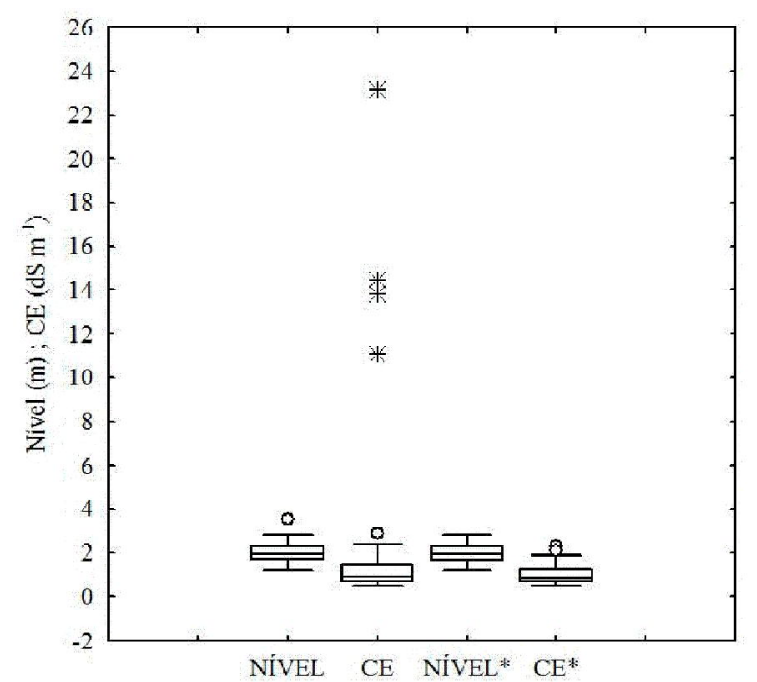

B.

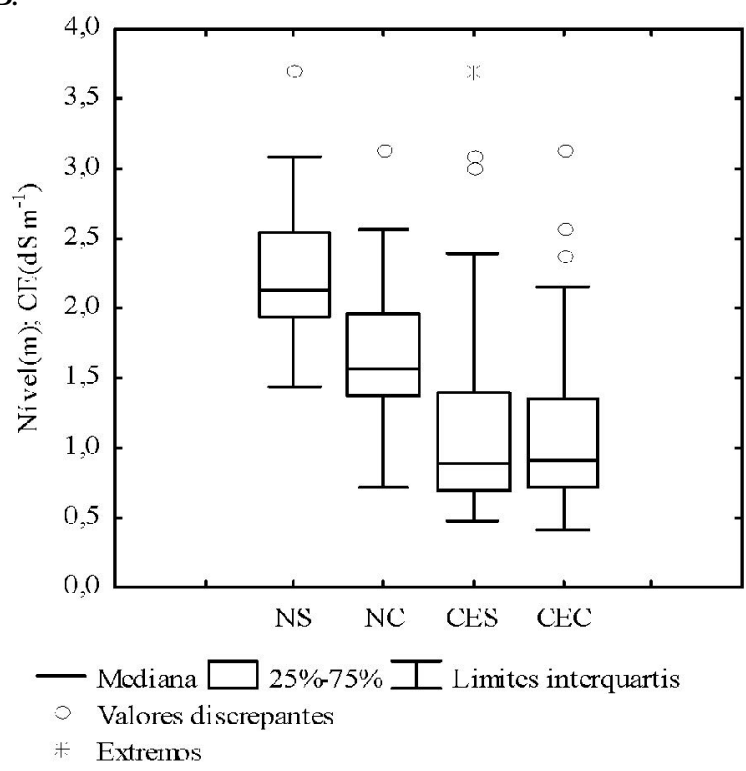

NS (nível periodo seco), NC (nível período chuvoso), CES (condutividade elétrica período seco) e CEC (condutvidade clétriea periodo chuvoso)

Figura 3. Box-plot do nível e condutividade elétrica. As variáveis N ível* e CE* representam os valores com filtragem dos dados discrepantes (A). Box-plot das variáveis para o período seco e chuvoso (B) determinado pelos padrões sazonais de chuva e escoamento superficial enquanto a dinâmica salina é menos evidente; desta forma, outros fatores, dentre eles heterogeneidades de condutividade hidráulica e a ocorrência de impedimentos geológicos, interferem na dinâmica de sais nas águas subterrâneas.

A Figura 4 apresenta a classificação pedológica dos solos do vale aluvial com destaque para alguns piezômetros, que apresentaram maior estabilidade.

Tweed et al. (2011) destacam que a distribuição espacial e temporal de sais em aquíferos com lençol freático raso é influenciada não apenas pelas zonas de recarga como também pela ocorrência de regiões de descarga, em que predominam fluxos de evaporação do lençol; esses fluxos, por sua vez, contribuem para o acúmulo de sais no perfil não saturado e para a ocorrência de salinização secundária; com efeito, zonas de descarga podem ser identificadas na unidade pedológica RU6 próximas ao contorno Norte do Vale (Figura 4), com lençol freático raso e apresentando elevada condutividade elétrica, conforme mapeado por Andrade et al. (2012). Contribuem para a reduzida profundidade do lençol nesta área a ocorrência de recarga lateral proveniente das encostas do vale, a microtopografia local que restringe a drenagem lateral e a existência de impedimentos geológicos. Também se observam regiões com elevado grau de compactação (Santos et al., 2012).

Para esta mesma unidade pedológica se encontram, porém, piezômetros que se mostraram representativos no tocante ao nível e à salinidade $(\mathrm{Pz}(\mathrm{P} 4) \mathrm{Pz} 3.8, \mathrm{Pz} 3.11 \mathrm{~b})$, cujo lençol freático é mais profundo. A profundidade mais elevada do lençol freático permite uma circulação hídrica maior e diluição de sais durante os eventos pluviométricos de intensidade elevada, conforme ressaltado por Burte et al. (2011) e Tweed et al. (2011).

A identificação dos piezômetros representativos para a média dos valores de nível e condutividade elétrica foi realizada a partir dos gráficos de estabilidade temporal (Figura 5) em que os piezômetros com diferenças relativas positivas tendem a superestimar os valores enquanto os de diferenças relativas negativas são os que subestimam a média.

No tocante aos níveis, os piezômetros que se mostraram representativos foram os $\mathrm{Pz}(\mathrm{P} 4), \mathrm{Pz} 3.8$ e $\mathrm{Pz} 4.6$ (Figura 5A) apresentando, respectivamente, as seguintes diferenças relativas médias, em valor absoluto: 0,015; 0,017 e 0,039 e desvios de 9,67, 6,64 e 8,45\%, respectivamente. Referidos piezômetros se localizam nas unidades de solo RU1 e RU6, conforme Figura 4. 


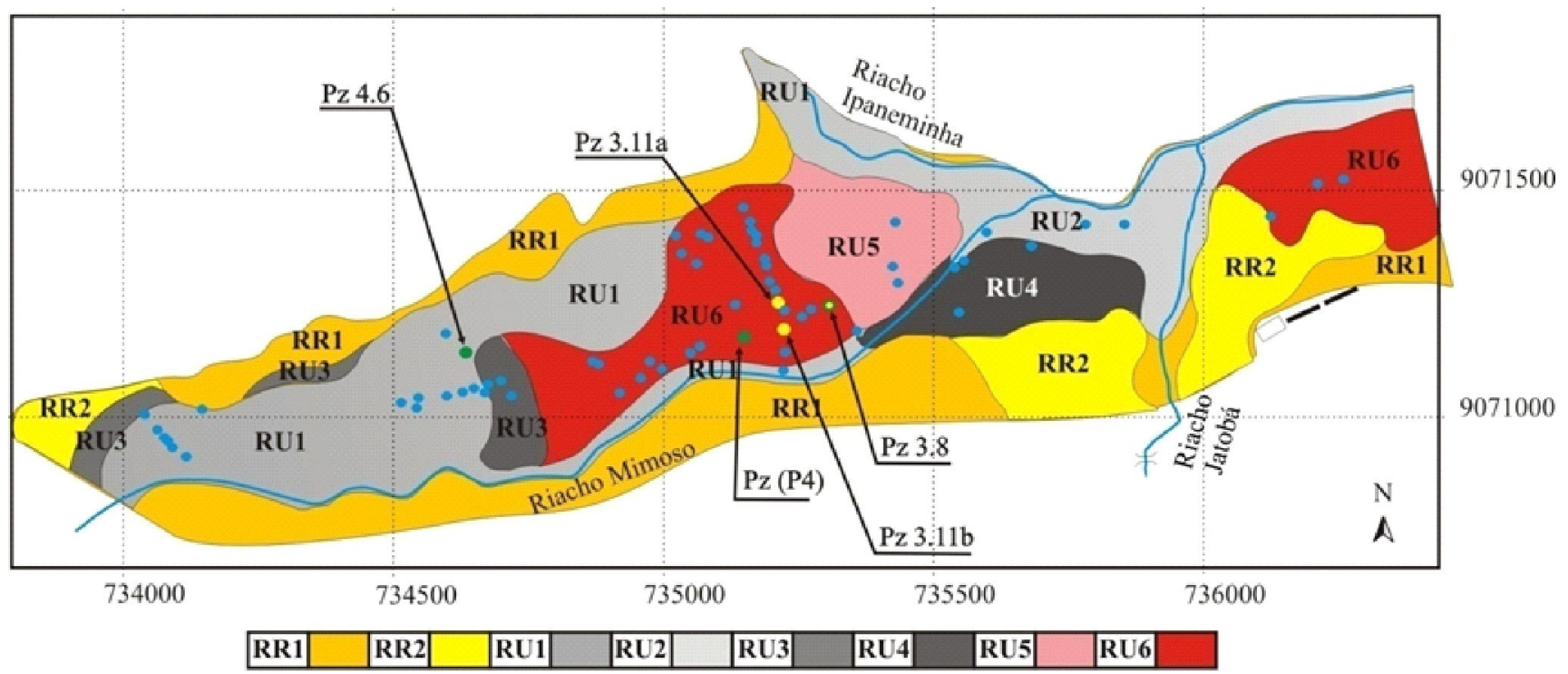

Pontos de Monitoramento do Nivel do Lençol e da CE

Piezômetros de maior estabilidade para o Nivel do Lençol

Piezômetros de maior estabilidade para a Condutividade Elétrica

RR1 NEOSSOLO REGOLÍTICO Eutrófico léptico + NEOSSOLO LITÓLICO Eutrófico típico ambos fase relevo suave ondulado;

RR2 NEOSSOLO REGOLÍTICO Eutrófico solódico textura média (leve) fase relevo plano e suave ondulado;

RU1 NEOSSOLO FLÚVICO Tb Eutrófico tipico textura arenosa ou média (leve) / média (leve) ou arenosa moderamente drenado;

RU2 NEOSSOLO FLÚVICO Tb Eutrófico tipico textura média / média (leve) ou arenosa moderamente drenado;

RU3 NEOSSOLO FLÚVICO Sódico típico textura média (leve) / média moderamente drenado;

RU4 NEOSSOLO FLƯVICO Sódico tipico textura média / média ou arenosa moderamente drenado;

RU5 NEOSSOLO FLÚVICO Sódico salino textura média / média (leve) ou média imperfeitamente drenado;

RU6 NEOSSOLO FLÚVICO Salino sódico textura média imperfeitamente drenado.

Figura 4. M apa da classificação pedológica da área em estudo (Correa \& Ribeiro, 2001) e localização dos piezômetros

A estabilidade do nível está associada à localização dos piezômetros confirmando análise anterior de Montenegro et al. (2003) ao afirmarem que, ao longo do eixo longitudinal do vale aluvial, os piezômetros exibem aproximadamente a mesma dinâmica de flutuação do nível da água ao longo do tempo. A proximidade dos riachos (Figura 4) pode influenciar esta estabilidade, por contribuir com recargas laterais.

Para a condutividade elétrica os piezômetros representativos para o valor médio da diferença relativa foram $\mathrm{Pz} 3.8, \mathrm{Pz} 3.11 \mathrm{be}$ Pz 3.11a (Figura 5B), que apresentaram diferenças relativas médias, em valor absoluto, de $0,062,0,002$ e 0,031 , respectivamente, e desvios de 10,85, 12,52 e 15,05\%, respectivamente. Todos se localizam na área de solo RU6 (Figura 4) como já comentado. Observa-se que o Pz 3.8 foi o de menor desvio, com diferença relativa próxima de zero tanto para nível quanto para a condutividade elétrica, embora apresentando desvio superior a $10 \%$ para esta última variável, que é considerado elevado, segundo Martinez-Fernandez \& Ceballos (2003). Este elevado desvio padrão temporal é indicativo da influência de processos localizados na variabilidade da condutividade elétrica podendo-se citar o cultivo irrigado em lotes de pequenas dimensões, dispersos no perímetro.

A Tabela 2 apresenta a condutividade hidráulica saturada dos piezômetros estáveis segundo Montenegro (1997) tanto para o nível quanto para a salinidade. Comparando-se esses valores com a média geométrica de $5,80 \mathrm{~m} \mathrm{~d}^{-1}$ de todos os piezômetros, pode-se verificar que os piezômetros estáveis apresentam condutividade hidráulica média a alta, com exceção de um dos piezômetros estáveis para salinidade.

As funções de probabilidade acumulada para os meses chuvosos (abril a julho) e meses secos (agosto a maio) de 2005 a 2010 para o nível do lençol freático e condutividade elétrica, estão apresentadas na Figura 6; nota-se que o aquífero aluvial apresenta sazonalidade em relação ao nível potenciométrico, com distinção entre os períodos secos e chuvosos, o mesmo não ocorrendo com a condutividade elétrica.

A validação da escolha dos piezômetros estáveis foi realizada a partir da comparação dos valores mensais dos piezômetros com a média dos demais piezômetros no tempo estudado. Para confirmar a adequação dos piezômetros representativos em relação à malha de piezômetros analisada, foram consideradas as medidas mensais para o nível potenciométrico (Figura 7) e condutividade elétrica (Figura 8) e comparada com as médias mensais dos piezômetros restantes para as duas variáveis analisadas. Esta comparação também foi utilizada por Martinez-Fernández \& Ceballos (2003, 2005) o que possibilitou uma validação adequada de pontos estáveis para a umidade do solo.

Os coeficientes de determinação calculados se situaram entre 0,95 e 0,81 ; o comportamento do nível dos piezômetros $\mathrm{Pz}(\mathrm{P} 4), \mathrm{Pz} 3.8$ e Pz 4.6 (Figura 7B, D e F) referente à média global, representa adequadamente a sazonalidade da recarga 

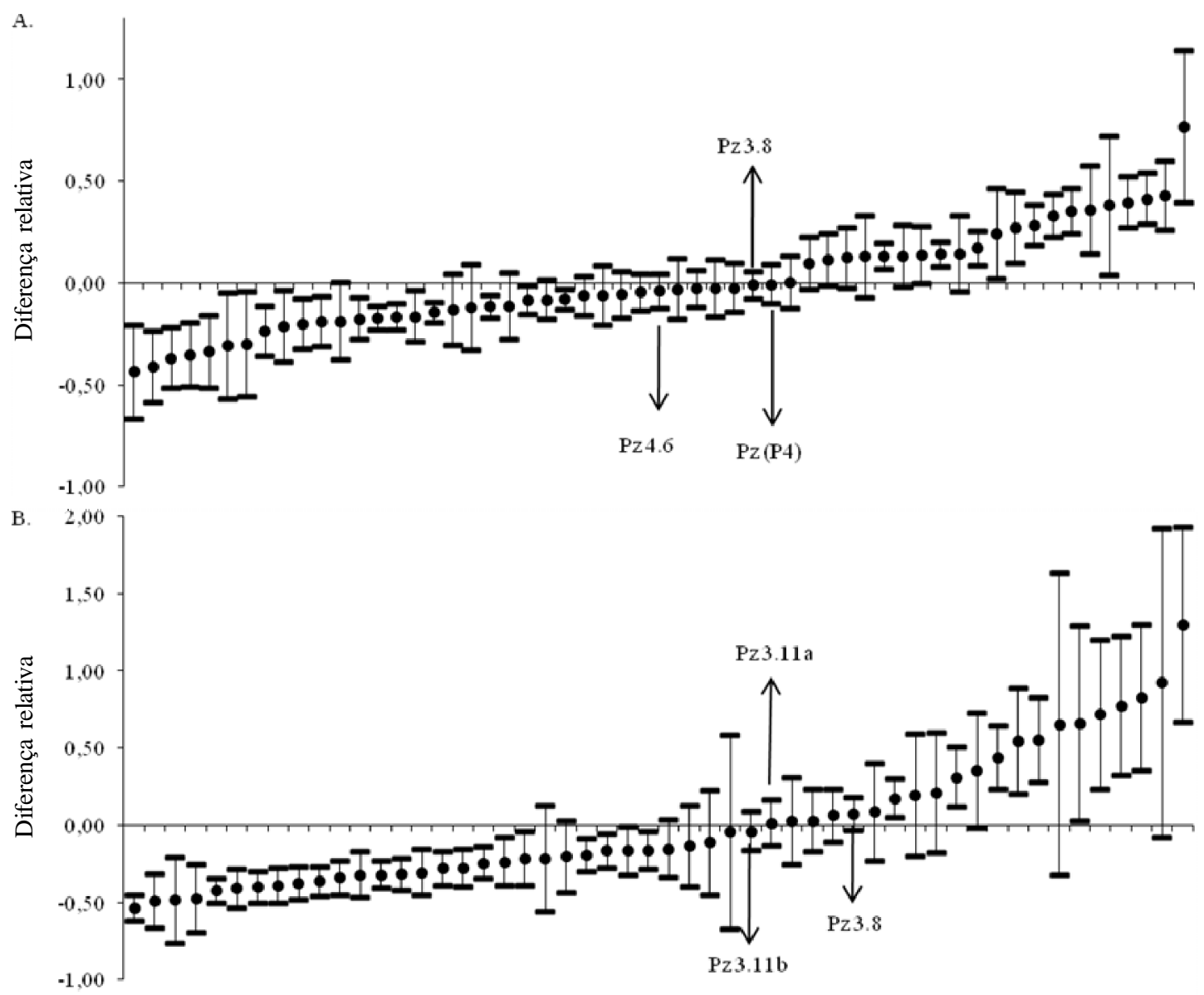

-Difer. Relativa Média Piezómetros I Desvio Padrão Temporal

Figura 5. Diferença relativa média intertemporal e desvio-padrão temporal para o nível potenciométrico (A) e condutividade elétrica (B)

Tabela 2. Condutividade hidráulica saturada dos piezômetros estáveis para nível potenciométrico e salinidade

\begin{tabular}{crcr}
\hline $\begin{array}{c}\text { Piezômetros estáveis } \\
\text { para o nível }\end{array}$ & $\mathbf{K}\left(\mathbf{m ~ d}^{-1}\right)$ & $\begin{array}{c}\text { Piezômetros estáveis } \\
\text { para a salinidade }\end{array}$ & $\mathbf{K}\left(\mathbf{m ~ d}^{-1}\right)$ \\
Pz (P4) & 25,12 & Pz 3.8 & 21,10 \\
Pz 3.8 & 21,10 & Pz 3.11a & 43,80 \\
Pz 4.6 & 116,00 & Pz 3.11b & 4,80 \\
\hline
\end{tabular}

Fonte: Montenegro (1997)

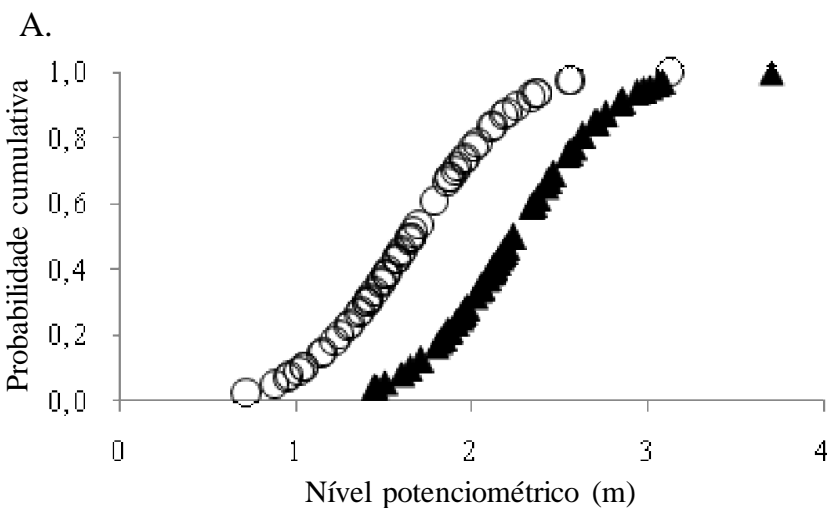

no aquífero constituindo-se em estimadores adequados do comportamento do nível. A estabilidade da sazonalidade dos níveis está diretamente associada com os processos de recarga, como salientado por Burte et al. (2011).

A estabilidade para o nível é confirmada nos gráficos do comportamento das médias com baixas variações entre os piezômetros estáveis e a média dos demais (Figura 7B, D e E). Observando-se a Tabela 2 com os valores de condutividade

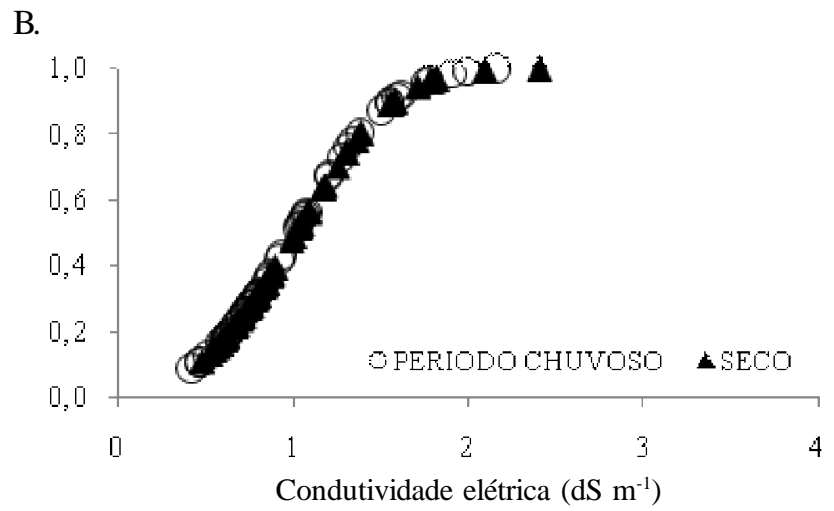

Figura 6. Função de probabilidade acumulada da média do nível potenciométrico (A) e da condutividade elétrica (B) dos piezômetros nos meses mais chuvosos e mais secos 


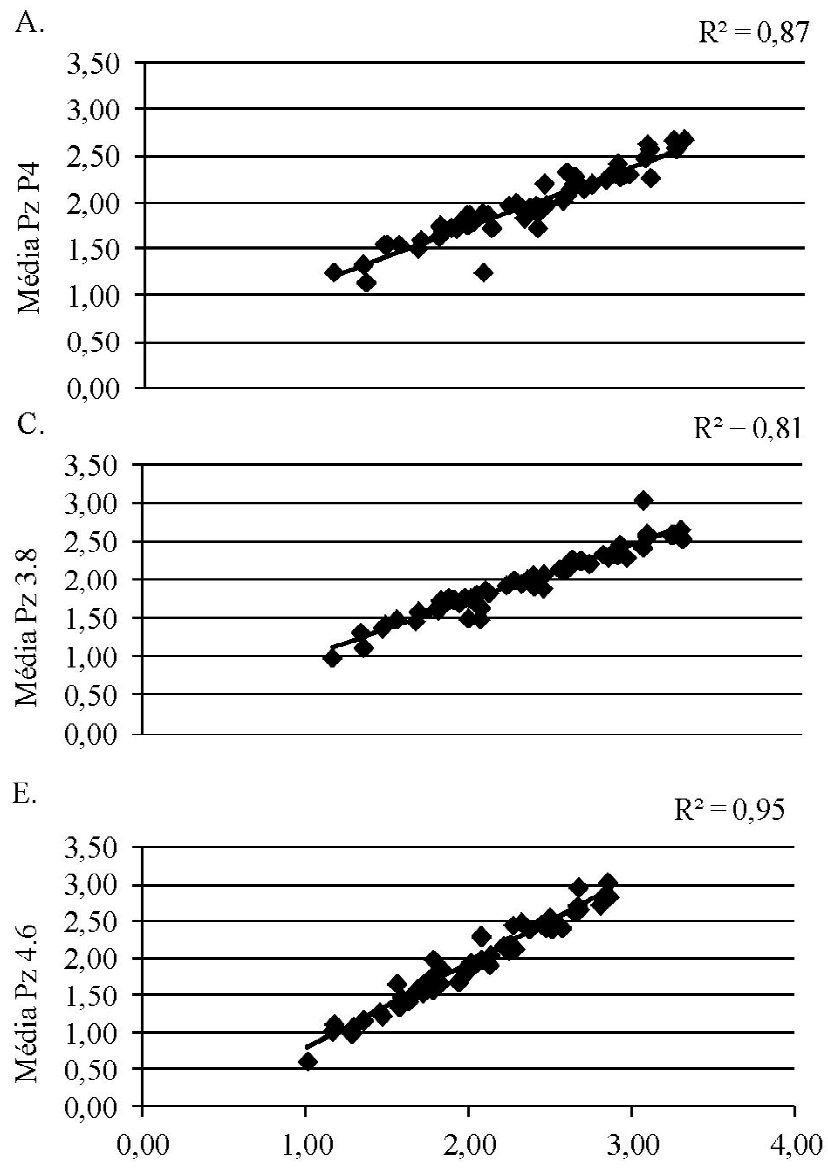

Média do Nível (m) dos demais Pièômelros
B.
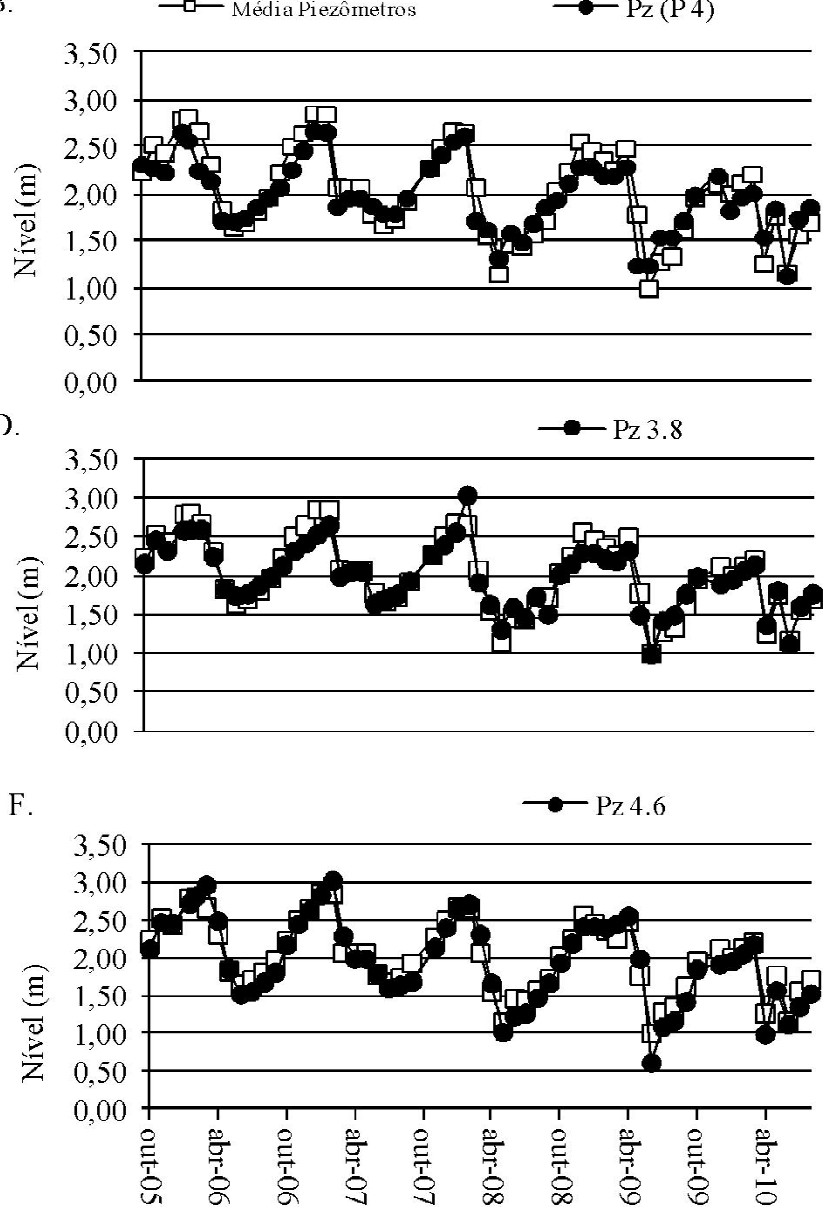

Mcses

Figura 7. Correlação entre os dados dos piezômetros estáveis e a média dos demais piezômetros ( $A, C$ e $E)$ e evolução do nível potenciométrico $(\mathrm{m})(B, D$ e $F)$ no período em estudo

hidráulica e se verificando os coeficientes de determinação da Figura 7A, C e E, pode-se constatar que os piezômetros estáveis apresentam condutividade hidráulica de média a alta. Os níveis potenciométricos nos piezômetros estáveis apresentam persistência temporal adequada e alta dependência a eventos de recarga, em particular no período de chuvas entre 2008 e 2010 (Figura 2). Burte et al. (2005) também observaram tal dependência analisando o comportamento de aquífero aluvial na Bacia de Forquilha, no Ceará.

No tocante à condutividade elétrica os coeficientes de determinação ficaram entre 0,01 e 0,34 , não validando os piezômetros com menores diferenças relativas mais próximas a zero. Observando as Figuras 8B, D e F, no período de abril de 2008 a abril de 2010 nota-se que alguns meses apresentaram médias mensais globais dos piezômetros inferiores e superiores às dos piezômetros estáveis. A não validação da estabilidade dos piezômetros em relação à condutividade elétrica pode ser explicada pela baixa amplitude de variação das condutividades elétricas médias (Figuras 8A, C e E). Analisando a Figura 6B, pode-se notar que o cálculo da média das condutividades elétricas no tempo produz excessiva suavização na variabilidade deste atributo, motivada pela não estacionaridade da salinidade no vale. Dentre os fatores que contribuem para a não estacionaridade da condutividade se destacam a ocorrência de condicionantes geológicos e a existência de regiões de descarga, distintas das áreas susceptíveis a processos predominantes de recarga, como já comentado; adicionalmente, o desenvolvimento da irrigação em lotes de pequenas dimensões distribuídos no vale, de forma empírica e independente, contribui para tal comportamento.

Vachaud et al. (1985) destacam que a metodologia da estabilidade temporal pode não ser representativa para alguns atributos, recomendando sua verificação para o atributo de interesse.

Os desempenhos da correlação avaliados através dos índices de Willmott entre os piezômetros estáveis e os demais, encontram-se na Tabela 3. Os desempenhos apresentados para os níveis foram de bom a ótimo enquanto a salinidade apresentou, em sua maioria, desempenho péssimo; a metodologia de Willmott não possibilitou validar os piezômetros de menor desvio para a condutividade elétrica, o que é consistente com a análise do coeficiente de determinação e como indicativo de que desvios padrões temporais superiores a $10 \%$ correspondem a baixo grau de dependência temporal. 

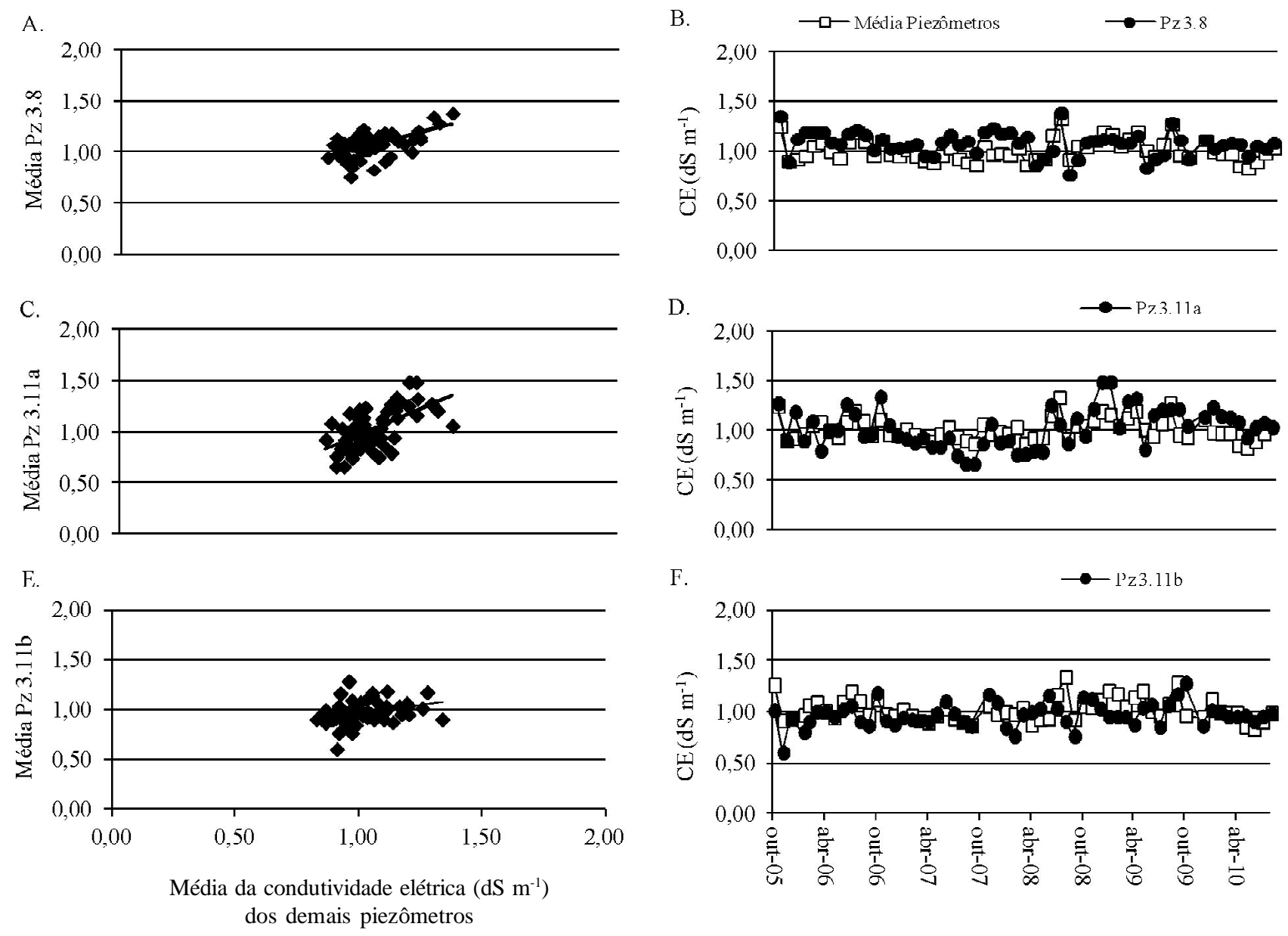

Figura 8. Correlação entre os dados dos piezômetros estáveis e a média dos demais piezômetros ( $A, C$ e E) e evolução

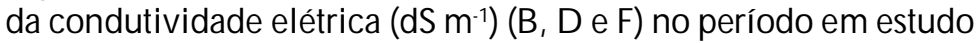

Tabela 3. Índice de Willmott e desempenho da estabilidade dos piezômetros

\begin{tabular}{lccc}
\hline \multicolumn{1}{c}{ Piezômetros } & Índice de Willmott & C & Desempenho \\
A. Estáveis nível & & & \\
Pz (P 4) & 0,91 & 0,74 & Bom \\
Pz 3.8 & 0,94 & 0,93 & Ótimo \\
Pz 4.6 & 0,99 & 0,96 & Ótimo \\
\hline B. Estáveis salinidade & & & \\
Pz 3.8 & 1,00 & 0,29 & Péssimo \\
Pz 3.11a & 0,99 & 0,55 & Sofrível \\
Pz 3.11b & 0,99 & 0,18 & Péssimo \\
\hline
\end{tabular}

\section{CONClusÕES}

1. Verificou-se ocorrência de estabilidade temporal do nível potenciométrico no aquífero aluvial, sendo possível identificar piezômetros que representam adequadamente a média da profundidade do lençol, no aluvião em questão.

2. As análises de estabilidade da condutividade elétrica e as validações desenvolvidas permitiram constatar que no aquífero em estudo nenhum piezômetro analisado apresentou estabilidade temporal, para a condutividade elétrica.

3. A estabilidade temporal para o nível potenciométrico ocorreu em piezômetros mais próximos ao leito do rio.
4. A dinâmica temporal dos níveis piezométricos em aluvião do semiárido está fortemente associada aos processos sazonais de recarga subterrânea enquanto a dinâmica das condutividades elétricas é influenciada por processos adicionais, de escala local.

\section{Agradecimentos}

Os autores agradecem ao CNPq, Finep e à FACEPE, pelo apoio no desenvolvimento deste estudo.

\section{LITERATURA CITADA}

Andrade, E. M. A irrigação e suas implicações sobre o capital natural em regiões áridas e semiáridas: Uma revisão. Revista Ceres, v.56, p.390-398, 2009.

Andrade, T. S.; Montenegro, S. M. G. L.; Montenegro, A. A. A.; Rodrigues; D. F. B. Variabilidade espaço-temporal da condutividade elétrica da água subterrânea na região semiárida de Pernambuco. Revista Brasileira de Engenharia Agrícola e Ambiental, v.16, p.496-504, 2012. 
Audry, P.; Suassuna, J. A salinidade das águas disponíveis para a pequena agricultura no Sertão Nordestino: Caracterização, variação sazonal, limitação e uso. Recife: CNPq. 1995. 128p.

Bastos, D. C. O.; Montenegro, A. A. A.; Montenegro, S. M. G. L. Avaliação de alternativa de irrigação suplementar com água moderadamente salina em vale aluvial no semiárido: experimentação e modelagem. Revista Brasileira de Recursos Hídricos, v.14, p.27-36, 2009.

Brooca, L.; Melone, F.; Moramarco, T.; Morbidelli, R. Soil moisture temporal stability over experimental areas in Central Italy. Geoderma, v.148, p.364-374, 2009.

Burte, J.; Coudrain, A.; Frischkorn, H.; Chaffaut, I.; Kosuth, P. Impacts anthropiques sur les termes du bilan hydrologique d'un aquifer alluvial dans le Nordeste semi-aride, Brésil. Hydrological Sciences - Journal dês Sciences Hydrologiques, v.50, p.95-110, 2005.

Burte, J.; Coudrain, A.; Marlet, S. Use of water from small alluvial aquifers for irrigation in semi-arid regions. Revista Ciência Agronômica, v.42, p.635-643, 2011.

Camargo, F. J. A.; Sentelhas, P. C. Avaliação do desempenho de diferentes métodos de estimativa da evapotranspiração potencial no Estado de São Paulo, Brasil. Revista Brasileira de Agrometorologia, v.5, p.89-97, 1997.

Corrêa, M. M; Ribeiro, M. R. Levantamento detalhado de solos da Fazenda Nossa Senhora do Rosário (Pesqueira-PE). Recife: UFRPE/UFPE/CNPq/BNB. 2001. 35p. Relatório Técnico

Hoaglin, D. C.; Mosteller, F.; Tykey, J. W. Análisis exploratória de datos: Técnicas robustas, un guia. Lisboa: Salamandra, 1983. 446p.

Mackay, R.; Montenegro A. A. A.; Montenegro, S. M. G. L.; Wonderen, J. V. Alluvial aquifer indicators for small-scale irrigation in northeast Brazil. In: Sustainability of groundwater resources and its indicators, Symposium S3 IAHS Scientific Assembly, Proceedings... v.302, 2006, p.117-125.

Martínez-Fernandez, J.; Ceballos, A. Temporal stability of soil moisture in a large-field experiment in Spain. Soil Science Society of America Journal, v.67, p.1647-1656, 2003.

Martínez-Fernandez, J.; Ceballos, A. Mean soil moisture estimation using temporal stability analysis. Journal of Hydrology, v.312, p.28-38, 2005.

Melo Filho, J. F.; Libardi, P. L. Estabilidade temporal de medidas do teor e do potencial mátrico da água no solo em uma transeção. Revista Brasileira de Ciência do Solo, v.29, p.497506, 2005.

Moiwo, J. P.; Yang, Y.; Li, H.; Han, S.; Hu, Y. Comparison of Grace with in situ hydrological measurement data shows storage depletion in Hai River basin, Northern China. Water SA, v.35, p.663-670, 2009.
Montenegro, A. A. A. Stochastic Hydrologeological modelling of aquifer salinization from small scale agriculture in Northeast Brazil. University of Newcastle, 1997. 272p. PhD Thesis

Montenegro, A. A. A.; Montenegro, S. M. G. L. Variabilidade espacial de classes de textura, salinidade e condutividade hidráulica de solos em planície aluvial. Revista Brasileira de Engenharia Agrícola e Ambiental, v.10, p.30-37, 2006.

Montenegro, A. A. A.; Netto, M. L. C.; Montenegro, S. M. G. L.; Silva, E. F. F.; Fontes Júnior, R.V.P. Avaliação da salinidade em Neossolo usando-se dispositivo de indução eletromagnética. Revista Brasileira de Engenharia Agricola e Ambiental, v.14, p.608-617, 2010b.

Montenegro, S. M. G. L.; Montenegro, A. A. A.; Mackay, R.; Oliveira, A. S. C. Dinâmica hidro-salina em aquífero aluvial utilizado para agricultura irrigada familiar em região semiárida. Revista Brasileira de Recursos Hídricos, v.8, p.85-92, 2003.

Montenegro, S. M. G. L.; Montenegro, A. A. A.; Ragab, R. Improving agricultural water management in the semi-arid region of Brazil: experimental and modelling study. Irrigation Science, v.28, p.301-316, 2010a.

Santos, K. S.; Montenegro, A. A. A.; Almeida, B. G.; Montenegro, S. M. G. L.; Andrade, T. S.; Fontes Júnior, R. V. P. Variabilidade espacial de atributos físicos em solos de vale aluvial no semiárido de Pernambuco. Revista Brasileira de Engenharia Agrícola e Ambiental, v.16, p.828-835, 2012.

Santos, T. E. M; Silva, D .D.; Montenegro, A. A. A. Temporal variability of soil water content under different surface conditions in the semiarid region of the Pernambuco State. Revista Brasileira de Ciência do Solo, v.34, p.1733-1741, 2010.

Sophocleous, M. A. Combining the soilwater balance and waterlevel fluctuation methods to estimate natural groundwater recharge: Practical aspects. Journal of Hydrology, v.124, p.229-241, 1991.

Souza, E. R.; Montenegro, A. A. A.; Montenegro, S. M. G. G.; Matos, J. A. Temporal stability of soil moisture in irrigated carrot crops in Northeast Brazil. Agricultural Water Management, v.99, p.26-32, 2011.

Tweed, S.; Leblanc, M.; Cartwright, I; Favreau, G; Leduc, C. Arid zone groundwater recharge and salinisation processes: an example from the Lake Eyre Basin, Australia. Journal of Hydrology, v.408, p.257-275, 2011.

Vachaud, G.; Silans, A. P.; Balabanis, P.; Vauclin, M. Temporal stability of spatially measured soil water probability density function. Soil Science Society of America Journal, v.49, p.822$827,1985$.

Willmott, C. J.; Ckleson, S. G.; Davis, R. E. Statistics for the evaluation and comparision of models. Journal of Geophysical Research, v.90, p.8995-9005, 1985. 